\title{
QUERCETIN INFLUENCES BSA ALPHA-HELICAL STRUCTURES OF NATIVE, ACR- AND $\mathrm{NaNO}_{2}$-MODIFIED BSAS
}

\author{
ANNA RORBACH-DOLATA ${ }^{1}$, EWA ŻURAWSKA-PŁAKSEJ ${ }^{2 *}$ \\ and AGNIESZKA PIWOWAR ${ }^{1}$
}

\author{
${ }^{1}$ Department of Toxicology, Faculty of Pharmacy, Wrocław Medical University, Poland \\ ${ }^{2}$ Department of Pharmaceutical Biochemistry, Faculty of Pharmacy, \\ Wrocław Medical University, Poland
}

\begin{abstract}
Quercetin (QUE) is a plant flavonoid with a multifarious spectrum of properties. It is a prominent component of the human diet, considered to be safe and beneficial for human health. Acrylamide (ACR) and sodium nitrate III $\left(\mathrm{NaNO}_{2}\right)$ are also present in the diet and may demonstrate adverse and toxic effects on the macromolecules and tissues of the human organism. Albumin, the most abundant blood protein, is the most susceptible to the action of various exogenous factors, which may lead to structural damage and functional disturbances. The aim of this study was to estimate ACR- and $\mathrm{NaNO}_{2}$-induced changes in the secondary structure of bovine serum albumin (BSA), using circular dichroism (CD), and to determine the impact of quercetin on these modifications. BSA was incubated with ACR and $\mathrm{NaNO}_{2}$ solutions in the absence and presence of QUE in two different concentrations ( $3 \mathrm{mM}$ and $500 \mu \mathrm{M})$, and changes in albumin alpha-helical structure were determined by $\mathrm{CD}$. The BSA secondary structure was vulnerable to alterations upon treatment with acrylamide and $\mathrm{NaNO}_{2}$, as well as quercetin. QUE, depending on concentration and incubation time, caused a decrease of around 13$19 \%$ in the alpha helix content of BSA molecules, but also prevented the changes in the protein alpha-helical structure initiated by ACR and $\mathrm{NaNO}_{2}$. The most spectacular inhibition was revealed for QUE in lower concentrations after $24 \mathrm{~h}$ of incubation with $\mathrm{NaNO}_{2}$. Although QUE reveals a protective effect towards albumin modifications, it is difficult to unambiguously define whether this effect is advantageous, because quercetin itself causes alterations in BSA structure.
\end{abstract}

Keywords: quercetin, nitrosylation, alkylation, albumin, conformational changes, circular dichroism

Albumin is the most abundant protein in the human body, occurring in the blood lymph, cerebrospinal fluid, and interstitial fluid. Human serum albumin (HSA) accounts for approximately 55\% of total blood plasma proteins and reaches concentrations of up to $45 \mathrm{~g} / \mathrm{L}$. It takes part in many body functions, including the maintenance of normal blood colloid osmotic pressure, the transporting and storing of numerous endogenous and exogenous compounds, and antioxidant defense (1). Albumin is synthesized and secreted from the liver, and molecules are primarily composed of $\alpha$-helices (about $67 \%$ of the structure). It has nine double loops, spanning three homologous domains where binding sites are located. HSA can undergo post-translational modifications, some of which can affect its structure or inhibit current functions. Cysteine 34 in domain I seems to be the major target of these modifications (2). Changes in the structure of albumin may be also caused by various factors, both endogenous (such as high glucose concentration or oxidative stress) and exogenous (e.g. environmental or food-derived components) (3-6). Although numerous spectroscopic methods are available to assess alterations in the biological structures of proteins (e.g. ultravioletvisible, fluorescence, nuclear magnetic resonance, Raman and Fourier transform infrared spectroscopy), circular dichroism (CD) spectroscopy is often the technique of choice in many studies that investigate the influence of different agents on the secondary structure of a protein (7-9).

In scientific research, bovine serum albumin (BSA) is frequently used as a model protein in the substitution of HSA in in vitro experiments (10). Modification of the BSA molecule through alkylation or nitrosylation involves the introduction of an alkyl radical or nitric oxide, respectively, which bind covalently to the sulfhydryl group on the cys-

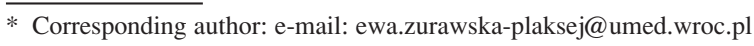


teine residue of a protein molecule (11). In the scientific literature, acrylamide (ACR) and sodium nitrate (III) $\left(\mathrm{NaNO}_{2}\right)$ are used as alkylating and nitrosating agents, respectively $(12,13)$. In this work, we intend to examine whether these agents may initiate modifications of BSA structure. The rationale for the selection of these two compounds for our study is their prevalence in food. ACR has been proven to be formed in potato and cereal products, which are subjected to heat treatment (at temperatures exceeding $120^{\circ} \mathrm{C}$ ), e.g. chips, French fries, crackers, and biscuits. The European Union Classification recognizes acrylamide as a carcinogen, mutagen and a factor contributing to infertility (14). Both nitrate (III) and (V) are commonly used in the food industry as preservatives for products of animal origin, in particular, fish, raw meats or rennet cheese (15). The nitrate itself is comparatively nontoxic, but roughly $5 \%$ of all ingested nitrate $(\mathrm{V})$ is converted in saliva and the gastrointestinal tract to the more toxic nitrate (III), which react with hemoglobin to form methemoglobin, and as a consequence impair oxygen delivery to tissue (16). The Scientific Committee on Food has estimated the acceptable daily intake of total nitrate as $3.7 \mathrm{mg} / \mathrm{kg}$ b. wt., and nitrate (III) as $0.07 \mathrm{mg} / \mathrm{kg}$ b. wt. (17).

Quercetin (QUE) is a plant flavonoid, with a multifarious spectrum of properties i.e. antioxidant, anti-inflammatory, antihypertensive, antimutagenic, anticarcinogenic and antiviral (18-20). As a result of its pervasive occurrence in plants, quercetin is a prominent component of the human diet and is considered to be safe and beneficial for human health (21). Consumption of quercetin is different across countries, a fact which is associated with dietary habits. Daily intake of products rich in flavonoids (of which about $75 \%$ is quercetin) ranges from $5 \mathrm{mg}$ to $80 \mathrm{mg}$ (22). The bioavailability of quercetin is relatively low $(<20 \%)$, which may be due to its low absorption, comprehensive metabolism and/or fast elimination (19). Quercetin, primarily in the form of glycosides, is found in the edible parts of plants, e.g. fruits, especially citrus, legumes, leafy vegetables, roots, tubers, and bulbs, but also in herbs and spices, cereal grains, cocoa, tea and wine (22-24). After a meal rich in flavonoids, they can be found in plasma as serum should be removed albumin-bound conjugates (25). The ability of QUE to bind to albumin contributed to the emergence of the theory about the protective effect of quercetin, especially with regard to xenobiotics, including drugs $(26,27)$. Recent studies show that high doses of quercetin have partial protective effects on toxicity induced by acrylamide. This protective ability results from to enhancement of the antioxidant defense system and free radical scavenging, regulation of fatty acids and amino acid metabolism $(28,29)$. Moreover, some epidemiologic studies suggest that an increase in the intake of dietary quercetin can reduce the risk of cardiac disease, some tumors, neurodegenerative diseases, and aging (28). Worth noting is that only a few in vitro studies report some damaging effects of quercetin (18). Most of the available literature indicates that quercetin used at estimated dietary intake levels do not produce adverse health effects (19).

The aim of this study was to estimate ACRand $\mathrm{NaNO}_{2}$-induced changes in the secondary structure of BSA using circular dichroism (CD), and determine the impact of quercetin on these modifications. The experimental scheme was based on the average concentrations of these agents in the human diet and their half-lives, which were supposed to imitate in vivo conditions.

\section{MATERIALS AND METHODS}

Bovine serum albumin fraction $\mathrm{V}$ (BSA), quercetin (QUE) and sodium nitrate III $\left(\mathrm{NaNO}_{2}\right)$ were purchased from Sigma-Aldrich Co. Acrylamide (ACR) was obtained from Raanal Budapest. All other chemicals used were of analytical grade. Stock solutions of BSA, ACR, $\mathrm{NaNO}_{2}$, and QUE were prepared as follows: $4 \mathrm{~g}$ of albumin was dissolved in $50 \mathrm{~mL}$ of PBS to achieve the concentration of $80 \mathrm{mg} / \mathrm{mL}(1.34 \mathrm{mM})$; the acrylamide solution was prepared through addition of $1.02 \mathrm{~g}$ of the substance into $20 \mathrm{~mL}$ of deionized water to achieve the concentration of $720 \mathrm{mM}$; the sodium nitrate solution was prepared through addition of $10.21 \mathrm{mg}$ of substance into $18.23 \mathrm{~mL}$ of deionized water to achieve the concentration of $8 \mathrm{mM} ; 72.5 \mathrm{mg}$ of quercetin was dissolved initially in $5 \mathrm{~mL}$ of DMSO and then $15 \mathrm{~mL}$ of PBS was added to achieve the concentration of $12 \mathrm{mM}$. The incubation mixtures were prepared by combining the appropriate volumes of reagent solutions, and the final concentrations of reagents are given below. The final concentration of DMSO in samples with quercetin did not exceed $6.25 \%$, remaining in accordance with spectroscopic measurements (30). However, control samples with DMSO solution were prepared, and no influence of this solvent was observed.

BSA incubation with acrylamide (13): BSA in the concentration of $40 \mathrm{mg} / \mathrm{mL}(0.67 \mathrm{mM})$, which reflects human plasma level (31), was incubated with: a) ACR (1.2 $\mu \mathrm{M}$ - corresponding to the maximal concentration of ACR in human diet and smoking habits); b) ACR and QUE1 (3 mM - concentra- 
tion corresponding to recommended doses of supplements available on the pharmaceutical market); c) ACR and QUE2 (500 $\mathrm{\mu M}$ - maximal concentration achieved in circulation considering its bioavailability) (32-34). The $\mathrm{pH}$ of these mixtures hovered between 7.4-7.6. The prepared mixtures were placed in flasks and incubated at $37^{\circ} \mathrm{C}$, in darkness, on a laboratory rotating platform Polymax 1040 (Heidolph) with a rotation of $50 \mathrm{rpm}$. Samples were taken after 1 and $24 \mathrm{~h}$ of incubation, which reflects a single dose and prolonged exposure to ACR, and dialyzed against PBS in the darkness at $4^{\circ} \mathrm{C}$ (35-36). The dialysis solution was changed three times: after $2 \mathrm{~h}, 4 \mathrm{~h}$ and $24 \mathrm{~h}$.

BSA incubation with sodium nitrate III (12): BSA at a concentration of $40 \mathrm{mg} / \mathrm{mL}(0.67 \mathrm{mM})$ was incubated with: a) $\mathrm{NaNO}_{2}(8 \mu \mathrm{M}$ - corresponding to average concentration in human diet), b) $\mathrm{NaNO}_{2}$ and QUE1, c) $\mathrm{NaNO}_{2}$ and QUE2 (37). To initiate the reaction, the environment was acidulated by $1 \mathrm{M}$ $\mathrm{HCl}$ (to $\mathrm{pH} 4$ ). All subsequent procedures were performed in the same way and with the same conditions as for the incubation of BSA with ACR.

Additionally a negative control (BSA-only solution) as well as a positive control (BSA with quercetin) were investigated and treated in the same way as the other samples. All experiments were performed in triplicate.

Protein concentration measurement: In all samples, after the dialysis procedure, protein concentration was measured spectrophotometrically, at a 280 nm wavelength (UV Genesys 10) after appropriate dilution.
Estimation of BSA secondary structure: Circular dichroism measurements of all samples were recorded on a JASCO J-1500 spectropolarimeter (205-250 nm) with a scanning speed of 200 $\mathrm{nm} / \mathrm{min}$, and the used cell length path was $0.1 \mathrm{~cm}$. The final plot was taken as an average of three accumulated plots. The baseline was corrected using PBS. BSA exhibits two characteristic negative bands in the UV region at 208 and $222 \mathrm{~nm}$, indicating that the protein has an $\alpha$-helical structure. The negative peaks are related from $\pi \rightarrow \pi^{*}(208 \mathrm{~nm})$ and $\mathrm{n} \rightarrow \pi^{*}(222 \mathrm{~nm})$ transitions for the peptide bond of the $\alpha$-helix (38). Next, the mean residue ellipticity (MRE) and alpha-helical content were calculated according to the following equations, respectively:

$$
M R E=\frac{\text { Observed } C D(\text { mdeg })}{C_{p} \cdot n \cdot l \cdot 10}
$$

where $C_{\mathrm{p}}$ is the molar concentration of the BSA, $n$ the number of amino acid residues (583 for BSA) and 1 is the path-length $(0.1 \mathrm{~cm})$;

$$
2 \alpha-\operatorname{helix}(\%)=\frac{M R E_{208}-4000}{33000-4000} \times 100
$$

where $M R E_{208}$ is the observed MRE value at $208 \mathrm{~nm}$, 4000 is the MRE of the $\beta$-form and random coil conformation cross at $208 \mathrm{~nm}$, and 33000 is the MRE value of the pure $\alpha$-helix of BSA at $208 \mathrm{~nm}$.

\section{RESULTS}

Circular dichroism spectroscopy was used to evaluate the modification of the secondary structure of the albumin, due to the effects caused by acryl-

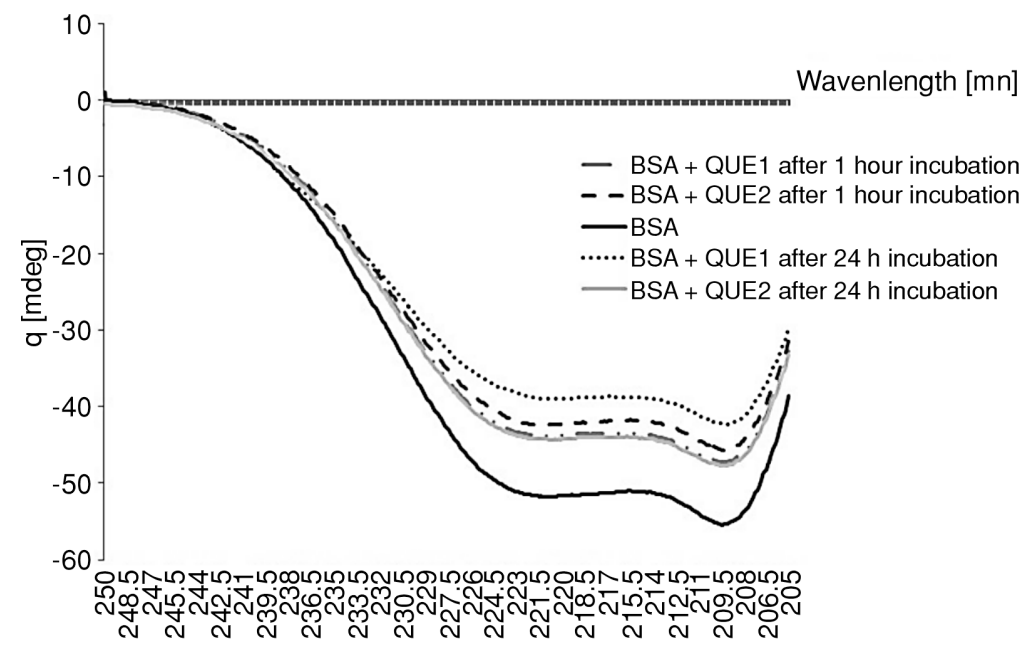

Figure 1. Circular dichroism spectra of bovine serum albumin (BSA) after 1 and $24 \mathrm{~h}$ incubation with quercetin at $3 \mathrm{mM}$ and $500 \mu \mathrm{M}$ concentration (QUE-1 and QUE-2, respectively) in relation to negative control (BSA-only) 
amide and sodium nitrate (III), as well as quercetin (alone and in the different combinations mentioned above). CD is very useful for studying the conformational changes of proteins upon binding with different ligands. This technique is appropriate for the monitoring of the possible influence of interaction processes on the structure of BSA, because of the high percentage of alpha-helical structure, with a characteristic CD signal (39-40).

Figure 1 presents the influence of QUE on the $\mathrm{CD}$ spectrum of BSA. We observed changes in BSA's characteristic CD pattern after incubation with quercetin. However, no time or concentrationdependent trend of changes exist. QUE-1 caused $13.43 \%$ of the changes in BSA alpha-helical structure after $1 \mathrm{~h}$ of incubation and $19.18 \%$ after $24 \mathrm{~h}$, and QUE-2 $16.08 \%$ and $12.86 \%$, respectively. The largest changes in the $\mathrm{CD}$ spectra were induced by QUE1 after $24 \mathrm{~h}$ of incubation.

Figure 2 presents the comparison of circular dichroism spectra of BSA obtained after 1 and $24 \mathrm{~h}$ incubation with ACR and $\mathrm{NaNO}_{2}$. Differences in the BSA characteristic CD pattern confirm the significant influence of these agents on BSA secondary structure. ACR caused smaller changes in the alphahelical structure in comparison with $\mathrm{NaNO}_{2}(9.90 \%$ vs. $23.51 \%$ after $1 \mathrm{~h}$ of incubation, respectively, and $22.88 \%$ vs. $26.57 \%$ after $24 \mathrm{~h}$ ). As shown, the longer incubation time caused intensification of the induced changes.
We also examined the CD spectrum of BSA after incubation with modifying agents (ACR and $\mathrm{NaNO}_{2}$ ) and quercetin in both concentrations (QUE1 and QUE-2) after $1 \mathrm{~h}$ and after $24 \mathrm{~h}$ incubation. Table 1 includes average alpha-helix content and calculated percentage changes of alpha-helical structure in all examined samples. QUE-1 inhibited changes of BSA alpha-helical structure induced by $\mathrm{NaNO}_{2}$ just after $1 \mathrm{~h}$ of incubation (by the amount of $7.67 \%$ ) and this outcome persisted after $24 \mathrm{~h}$ $(9.86 \%)$. Such an effect was not shown for ACR action. Moreover, the presence of quercetin caused even greater structural changes in the BSA molecule subjected to ACR in most cases. Only for QUE-2 after $24 \mathrm{~h}$ incubation changes of BSA structure were slightly smaller (2.23\%). Summarizing, QUE2 inhibited changes of BSA alpha-helical structure initiated both by ACR and $\mathrm{NaNO}_{2}$, and the most spectacular inhibition $(21.51 \%)$ was observed after 24 hours of incubation with $\mathrm{NaNO}_{2}$.

\section{DISCUSSION}

Acrylamide and nitrates are harmful chemicals, used in many industrial processes, that people inevitably encounter through processed food and drinking water (14-15). It is known that ACR exposure may cause neurotoxic and genotoxic effects, as well as disturbances in oxidative status in tissues (41-43). Sodium nitrate (III) is considered toxic due

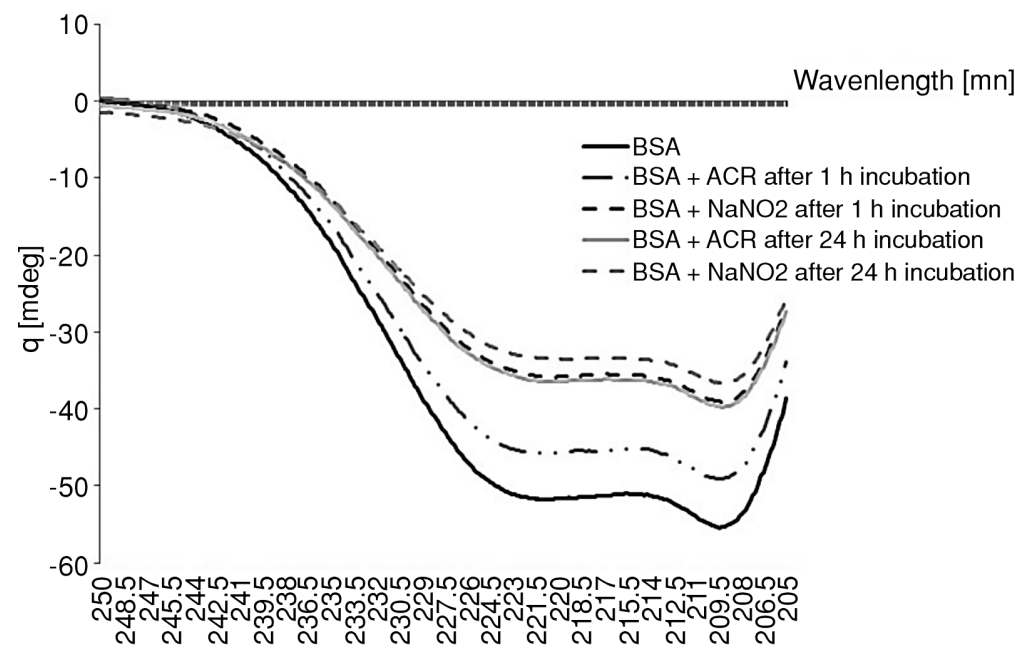

Figure 2. Circular dichroism spectra of bovine serum albumin (BSA) after 1 and $24 \mathrm{~h}$ incubation with acrylamide (ACR) and sodium nitrate (III) $\left(\mathrm{NaNO}_{2}\right)$ in relation to negative control (BSA-only) 
Table1. The alpha-helix content (\%) and calculated alpha-helical content changes (\%) of bovine serum albumin (BSA) in all examined samples after $1 \mathrm{~h}$ and $24 \mathrm{~h}$ incubation with acrylamide (ACR) and sodium nitrate (III) $\left(\mathrm{NaNO}_{2}\right)$ in the absence and presence of $3 \mathrm{mM}$ and $500 \mu \mathrm{M}$ quercetin solutions (QUE-1 and QUE-2, respectively).

\begin{tabular}{|l|c|c|c|c|}
\hline \multirow{2}{*}{ Sample } & \multicolumn{2}{|c|}{1 hour } & \multicolumn{2}{c|}{24 hours } \\
\cline { 2 - 5 } & $\begin{array}{c}\text { Alpha helix } \\
\text { content }(\%) \\
{[\text { mean } \pm \text { SD }]}\end{array}$ & $\begin{array}{c}\text { Alpha helical } \\
\text { content } \\
\text { changes }(\%)\end{array}$ & $\begin{array}{c}\text { Alpha helix } \\
\text { content }(\%) \\
{[\text { mean } \pm \text { SD] }}\end{array}$ & $\begin{array}{c}\text { Alpha helical } \\
\text { content } \\
\text { changes }(\%)\end{array}$ \\
\hline BSA & $65.81 \pm 0.8$ & & $65.81 \pm 0.8$ & \\
\hline BSA + QUE1 & $56.96 \pm 1.4$ & 13.43 & $53.18 \pm 0.7$ & 19.18 \\
\hline BSA + QUE2 & $55.22 \pm 1.1$ & 16.08 & $57.34 \pm 1.3$ & 12.86 \\
\hline BSA + ACR & $59.29 \pm 0.6$ & 9.90 & $50.74 \pm 0.9$ & 22.88 \\
\hline BSA + ACR + QUE1 & $45.50 \pm 0.8$ & 30.85 & $42.54 \pm 1.7$ & 35.35 \\
\hline BSA + ACR + QUE2 & $53.09 \pm 0.9$ & 19.32 & $52.21 \pm 1.4$ & 20.65 \\
\hline BSA + $\mathrm{NaNO}_{2}$ & $49.01 \pm 1.3$ & 23.51 & $48.32 \pm 1.2$ & 26.57 \\
\hline BSA + $\mathrm{NaNO}_{2}+$ QUE1 & $55.38 \pm 0.7$ & 15.84 & $54.80 \pm 0.5$ & 16.71 \\
\hline BSA + $\mathrm{NaNO}_{2}+$ QUE2 & $51.76 \pm 1.2$ & 21.34 & $62.47 \pm 0.8$ & 5.06 \\
\hline
\end{tabular}

to the potential carcinogenicity of derived N-nitroso compounds, however, recent research suggests that dietary nitrate may enter a "nitrate-nitrite-nitric oxide pathway" and serve as an alternative source of nitric oxide (44-46). Our study was designed to determine whether the secondary structure of BSA is vulnerable to change in the presence of the above compounds, applied in concentrations corresponding to the average content in the human diet. A few studies have already indicated that the albumin molecule is susceptible to alkylation by acrylamide as well as to nitrosylation by sodium nitrate $(6,47)$. To the best of our knowledge, there are no literature references regarding the influence of ACR and $\mathrm{NaNO}_{2}$ on the BSA molecule in the molar ratios we used (BSA:ACR was $1: 0.0018$ and BSA : $\mathrm{NaNO}_{2}$ was $1: 0.012$ ). The choice of such concentrations resulted from the possible daily dietary intake. It is not known whether the processes of alkylation and nitrosylation occur under these conditions. Since cysteine 34 is indicated by some authors (2-3) as the main target of possible modifications, we measured the concentrations of thiol groups using the Ellman method (48) after the dialysis procedure, and observed their slight decrease in samples containing both ACR and $\mathrm{NaNO}_{2},(\mathrm{BSA}+\mathrm{ACR} 10 \%$ decrease, $\mathrm{BSA}+\mathrm{NaNO}_{2} 15 \%$ decrease in comparison to control sample - BSA only), which may indicate the occurrence of alkylation and nitrosylation (data not shown). However, it is uncertain whether the $\mathrm{SH}$ group of cysteine 34 is the only site of alkylation and/or nitrosylation. Friedman et al. (49) reported that acrylamide may also attach to the amino groups of proteins. With regard to this, we chose CD spectroscopy as a tool to detect protein secondary structure changes initiated by ACR and $\mathrm{NaNO}_{2}$.

In our study, the small amounts of ACR and $\mathrm{NaNO}_{2}$ in experimental solutions were nonetheless enough to trigger changes in the secondary structure of BSA as derived from CD measurements and spectra analysis (Fig. 2). Distortions in the characteristic pattern of BSA observed in CD measurements suggest a partial unfolding of the protein chain and indicate that the intramolecular forces responsible for maintaining the secondary structure are altered (50). More significant changes after $1 \mathrm{~h}$ of incubation were triggered by $\mathrm{NaNO}_{2}(23.51 \%)$ in comparison with changes observed for ACR $(9.90 \%)$. The literature data are ambiguous. For example, Zhang et al. (51) did not confirm alterations in BSA conformation upon treatment with $\mathrm{NaNO}_{2}$, despite its higher concentration during nitrosylation reaction (molar ratio BSA : $\mathrm{NaNO}_{2}$ was $1: 1)$. In another study, they showed an increase of around 5\% in alpha-helical content and a decrease of the beta-pleated sheet (about 20\%) upon ACR treatment (molar ratio BSA : ACR was $1: 24$ ) (52). However, from our study it clearly emerged that both examined agents caused alterations in BSA secondary structure, as confirmed by the loss in negative ellipticity of CD spectra, indicating destabilization of the BSA helical structure (manifested by a decrease in alpha-helical content). Thus may indicate partial protein unfolding and structural transformation from $\alpha$-helix to $\beta$-sheet and random coil (53). The obtained results show the great sensitivity 
of albumin to the action of even small amounts of diet-derived xenobiotics, proving the importance of our research. Of course to fully understand the mechanism of BSA-ACR or BSA-NaNO $\mathrm{N}_{2}$ interactions, the thermodynamic parameters related to these complex formations should be calculated (54). Experiences in CD measurements show that reversible as opposed to irreversible binding is influenced by only small differences in protein secondary structure (55). Taking into account that the changes in alpha-helical structure obtained in our study are quite large - the maximal changes observed after $24 \mathrm{~h}$ of incubation were $22.88 \%$ for ACR and $26.57 \%$ for $\mathrm{NaNO}_{2}$, and that measurements of CD spectra were carried out after an intensive dialysis procedure in PBS buffer (which may partially break weak noncovalent bonds), and always in comparison with a control sample, we may assume that these changes derive mainly from covalent bonding.

We were curious about whether the addition of quercetin to our experimental model of ACR- and $\mathrm{NaNO}_{2}$-modified BSA would have any impact on its molecular structure. A quercetin-rich diet is generally recommended, particularly to prevent age-related diseases (56). It is known that quercetin is characterized by a high binding affinity to plasma proteins after release from the dosage form, and as a result, its cellular availability is poor (57). Some authors also indicate the binding affinity of quercetin to cellular DNA (58). $99.4 \%$ of administered quercetin is reported to be bound to serum albumin, and according to Boulton et al. (57) quercetin concentration has no significant effect on the bound-fraction. This means that only a small amount of the administered quercetin remains unbound and pharmacologically active. Some researchers suggest that quercetin, due to its phenolic structure, is rapidly oxidized in cells, presumably by different peroxidases, to products capable of covalently binding to albumin $(26,59)$. Binding studies with the use of warfarin, as well as molecular docking, have provided controversial results, but most of them indicate subdomain IIA as a major binding site for quercetin $(56,60)$. The values of binding constant of QUE-BSA obtained in different studies ranged from $9.8 \times 10^{4}$ to $49.5 \times 10^{4}$ $\mathrm{M}^{-1}$ (61-63). Therefore, the possibility of displacement of other ligands from this binding site exists, which may cause the elevation of their free plasma concentrations, leading to adverse effects, especially in patients suffering from kidney or liver diseases (64). Rimac et al. (60) tested the risk of drug displacement from HSA by quercetin and observed no direct interactions between warfarin and quercetin. Thus authors hypothesized that the formation of ter- nary HSA-warfarin-quercetin complex may occur. In our study, we tested two different concentrations of quercetin: $3 \mathrm{mM}$ (marked as QUE1) and $500 \mu \mathrm{M}$ (marked as QUE2), which correspond to high-dose supplementation and the concentration achieved in circulation, respectively $(39,40)$. We observed an obvious decrease in the intensity of negative bands appearing with the addition of quercetin, suggesting considerable changes in the protein secondary structure (Fig. 1). The alpha-helical content was reduced by $13-19 \%$, depending on quercetin concentration and incubation time. Taking into consideration that serum albumin is the major binding and transport protein for many endogenous and exogenous ligands (including drugs), changes in its structure may determine the pharmacokinetics of different substances capable of binding to the albumin molecule, and cause unexpected interactions. While the benefits of taking quercetin supplements have been widely discussed, little attention is paid to quercetin influence on the structure of serum albumin (65). Some circular dichroism data indicate that quercetin and other polyphenols, after binding to BSA, do not significantly change its secondary structure (66). However, our study clearly demonstrates that BSA secondary structure was altered after incubation with this flavonoid. It seems very interesting, whether flavonoids may also influence the structure of other proteins (67).

It is well known that alkylation and nitrosylation may also influence the binding capacity of albumin, for example, ACR $(2.8 \mathrm{mM})$ reduced the binding of vitamin B2 to BSA by almost one half (52). Some studies indicate the preventive effect of quercetin towards ACR exposure. El-Beltagi et al. (68) showed that oral administration of ACR induced elevation of inflammatory markers and oxidative stress parameters in rats, and coadministration of quercetin in dose 25 and $50 \mathrm{mg} / \mathrm{kg}$ ameliorated these unfavorable effects, which suggests that quercetin has a protective role in ACR-induced oxidative stress in the animal model. Yang et al. (69) also indicated that quercetin had a beneficial effect on the metabolic profile of the serum of ACR-treated rats. To our knowledge, there is no report of the influence of quercetin on BSA secondary structure modifications induced by $\mathrm{ACR}$ or $\mathrm{NaNO}_{2}$. In our study, we revealed the inhibitory properties of quercetin towards changes of BSA alpha-helical structure initiated by $\mathrm{NaNO}_{2}$, and the most spectacular inhibition was observed for QUE-2 after $24 \mathrm{~h}$ of incubation with this agent (Table 1). Such a protective effect was not shown for ACR. Moreover, structural changes in BSA subjected to ACR even 
increased in the presence of quercetin, with the exception of QUE-2 after $24 \mathrm{~h}$ ( $2 \%$ fewer changes). We hypothesize that this may result from the possible reaction between acrylamide and quercetin under in vitro conditions, which may adversely affect the BSA molecule. In summary, QUE-2, corresponding to concentrations which are possible to achieve by supplementation, inhibited structural changes of albumin initiated both by ACR and $\mathrm{NaNO}_{2}$ after longer times of incubation, which may indicate the positive effects of quercetin supplementation. However, it should be underlined that too high quercetin concentrations may aggravate these changes (Table 1). There are only two studies reporting the effect of the simultaneous presence of quercetin and sodium nitrate in the in vitro model, however, this research concerns sodium nitrate (V). Kurzeja et al (70) indicated disruption of the redox homeostasis and decreased ATP concentration in fibroblasts upon treatment of these compounds. The authors showed that exposure of the cells to nitrate inhibited their growth and in the presence of quercetin this inhibition was smaller. However, even prolonged exposure to quercetin did not result in the normalization of metabolic activity in the cells.

Our study clearly demonstrates that BSA secondary structure is vulnerable to alteration upon treatment with acrylamide and sodium nitrate (III), as well as quercetin. However, the influence of quercetin on ACR- and $\mathrm{NaNO}_{2}$-induced changes in the secondary structure of BSA is not unequivocal. It seems that quercetin at $500 \mu \mathrm{M}$ concentration exerts a preventive effect towards a BSA molecule subjected to $\mathrm{NaNO}_{2}$-exposure. It is difficult to determine whether this effect is advantageous, because quercetin itself causes alterations in BSA structure, as revealed by circular dichroism measurements.

\section{Acknowledgments}

The study was funded by internal grant ST-958 from Wroclaw Medical University.

The authors are grateful to Marta Leońska for the collection of literature data.

\section{REERENCES}

1. Krach-Hansen U., Chuang V.T.G., Otagiri M.: Biol. Pharm. Bull. 25, 695 (2002).

2. Lee P., Wu X.: Curr. Pharm. Design 21, 1862 (2015).

3. Oettl K., Stauber R.E.: Br. J. Pharmacol. 151, 580 (2007).
4. Belatik A., Hotchandani S., Carpentier R., Tajmir-Riahi H.A.: PLoS One 7, e36723 (2012)

5. Dolatabadi J.E.N., Vahid Panahi-Azar V., Barzegar A., Jamali A.A., Kheirdoosh F. et al.: RSC Adv. 4, 64559 (2014).

6. Noort D., Fidder A., Hulst A.G.: Arch. Toxicol. 77, 543 (2003).

7. Żurawska-Płaksej E., Rorbach-Dolata A., Wiglusz K., Piwowar A.: Spectrochim. Acta A Mol. Biomol. Spectrosc. 189, 625 (2018).

8. Mohan S., Hemachandran H., Sneha P., George Priya Doss C., Godwin C.J. et al.: J. Biomol. Struct. Dyn. DOI: 10.1080/07391102.2017. 1342565 (2017).

9. Hsieh S.R., Reddy P.M., Chang C.J., Kumar A., Wu W.C. et al.: Polymers 8, 238 (2016).

10. Chruszcz M., Mikolajczak K., Mank N., Majorek K.A., Porebski P.J. et al.: Biochim. Biophys. Acta 1830, 5375 (2013).

11. Martyniuk C., Feswick A., Fang B., Koomen J.M., Gavin T. et al.: Toxicol. Lett. 219, 279 (2014).

12. Ewing J.F., Young D.V., Janero D.R., Garvey D.S., Grinnell T.A.: J. Pharmacol. Exp. Ther. 283, 947 (1997).

13. Dixit R., Das M., Seth P.K., Mukhtar H.: Environ. Res. 40, 365 (1986).

14. Pingot D., Pyrzanowski K., Michałowicz J., Bukowska B.: Med. Pr. 64, 259 (2013).

15. Sindelar J.J., Milkowski A.L.: Nitric Oxide Biol. Chem. 26, 259 (2012).

16. Mensinga T.T., Speijers G.J., Meulenbelt J.: Toxicol. Rev. 22, 41 (2003).

17. EFSA.: EFSA J. 689, 1 (2008).

18. D'Andrea G.: Fitoterapia 106, 256 (2015).

19. Li Y., Yao J., Han C., Yang J., Chaudhry M.T. et al.: Nutrients 8, 1 (2016).

20. Majumder D., Das A., Saha C.: Int. J. Biol. Macromol. 104, 929 (2017).

21. Kobylińska A., Janas K.M.: Postepy Hig. Med. Dosw. 69, 51 (2015).

22. Chen S., Jiang H., Wu X., Fang J.: Mediators Inflamm. 2016, 9340637 (2016).

23. Brown J.P.: Mutat. Res. 75, 243 (1980).

24. Guo Y., Bruno R.S.: J. Nutr. Biochem. 26, 201 (2015).

25. Liu S., Guo C., Guo Y., Yu H., Greenaway F. et al.: Iran J. Pharm. Res. 13, 1019 (2014).

26. Kaldas M.I., Walle U.K., Van Der Woude H., McMillan J.M., Walle T.: J. Agric. Food Chem. 53, 4194 (2005).

27. Zargar S., Siddiqi N.J., Ansar S., Alsulaimani M.S., El Ansary A.K.: Pharm. Biol. 209, 1 (2016). 
28. Bao W., Cao C., Li S., Bo L., Zhang M. et al.: Food Funct. 8, 1204 (2017).

29. Uthra C., Shrivastava S., Jaswal A., Sinha N., Reshi M.S. et al.: Biomed. Pharmacother. 86, 705 (2017).

30. Taosheng C.: A Practical Guide to Assay Development and High-Throughput Screening in Drug Discovery 20 (2009).

31. Taverna M., Marie A.L., Mira J.P., Guidet B.: Ann. Intensive Care 15, 4 (2013).

32. Mojska H., Gielecińska I., Cendrowski A.: Ann. Agric. Environ. Med. 23, 456 (2016).

33. Malczyk E., Grochowska-Niedworok E., Wyka J., Misiarz M., Kacprzak M.: Bromat. Chem. Toksykol. 45, 685 (2012).

34. Li Y., Yao J., Han C., Yang J., Chaudhry M. et al.: Nutrients 15, 167 (2016).

35. Fuhr U., Boettcher M., Kinzig-Schippers M., Weyer A., Jetter A. et al.: Cancer Epidemiol. Biomarkers Prev. 15, 266 (2006).

36. Bondonno C., Liu A., Croft K., Ward N., Puddey I. et al.: Nutrients 12, 1906 (2015).

37. Dżugan M., Pasternakiewicz A.: Proceedings of ECOpole 1, 129 (2007).

38. Greenfield N.J.: Nat. Protoc. 1, 2876 (2006).

39. Gliszczyńska-Świgło A., Szymusiak H.: Żyw. Nauka Technol. Jakość 4, 278 (2009).

40. Scholten S.D., Sergeev I.N.: Open Access J. Sport Med. 4, 53 (2013).

41. Yousef M.I., El-Demerdash F.M.: Toxicology 219, 133 (2006).

42. Abdel-Daim M.M., Abd Eldaim M.A., Hassan A.G.A.: Biochem. Cell Biol. 93, 192 (2015).

43. Zhu Y.J., Zeng T., Zhu Y.B., Yu S.F., Wang Q.S. et al.: Neurochem. Res. 33, 2310 (2008).

44. Weitzberg E., Lundberg J.O.: Annu. Rev. Nutr. 33, 129 (2013).

45. Bondonno C.P., Croft K.D., Hodgson J.M.: Crit. Rev. Food Sci. Nutr. 56, 2036 (2016).

46. Lidder S., Webb A.J.: Br. J. Clin. Pharmacol. 75, 677 (2012).

47. Park J.W.: Arch. Pharm. Res. 16, 1 (1993).

48. Rice-Evans C.A., Diplock A.T., Symons M.C.R.: Techniques in Free Radical Research, New York, Tokyo: Elsevier, 207 (1991).

49. Friedman M.: J. Agric. Food Chem. 51, 4504 (2003).
50. Martin S.R., Schilstra M.J.: Methods Cell Biol. 84, 263 (2008).

51. Zhang Y., Xu A., Nomen M., Walsh M.: J. Biol. Chem. 271, 14271 (1996).

52. Zhang Y.L., Zhang X., Fei X.C., Wang S.L., Gao H.W.: J. Hazard. Mater. 182, 877 (2010).

53. Wiglusz K., Trynda-Lemiesz L.: J. Photochem. Photobiol. A. 89, 1 (2014).

54. Saini R.D.: J. Proteins Proteomics 8, 205 (2017).

55. Zhang H., Zhang M., Wang Y., Wang Y., Sunt S. et al.: J. Luminesc. 194, 519 (2018).

56. Di Bari L., Ripoli S., Pradhan S., Salvadori P.: Chirality 22, 593 (2010).

57. Boulton D.W., Walle U.K., Walle T.: J. Pharm. Pharmacol. 50, 243 (1998).

58. Das A., Majumder D., Saha C.: J. Photochem. Photobiol. B. 170, 256 (2017).

59. Walle T., Vincent T.S., Walle U.K.: Biochem. Pharmacol. 65, 1603 (2003).

60. Rimac H., Dufour C., Debeljak Ž., Zorc B., Bojić M.: Molecules 22, 1153 (2017).

61. Dufour C., Dangles O.: Biochim. Biophys. Acta 1721, 164 (2005).

62. Liu E.H., Qi L.W., Li P.: Molecules 15, 9092 (2010).

63. Choiprasert W., Loetchutinat C., Dechsupa N., Mankhetkorn S.: Am. J. Biochem. Biotechnol. 7, 10 (2011).

64. Varshney A., Rehan M., Subbarao N., Rabbani G., Khan R.H.: PLoS One 6, e17230 (2011).

65. Harwood M., Danielewska-Nikiel B., Borzelleca J.F., Flamm G.W., Williams G.M. et al.: Food Chem. Toxicol. 45, 2179 (2007).

66. Skrt M., Benedik E., Podlipnik Č., Ulrih N.P.: Food Chem. 135, 2418 (2012).

67. Pal S., Dey S.K., Saha C.: PLoS One 9, e102460 (2014).

68. El-Beltagi H., Ahmed M.M.: J. Food Biochem. 40, 715 (2017).

69. Yang J., Zhang Y.: Curr. Protoc. Bioinformatics 1 (2016).

70. Kurzeja E., Stec M., Synowiec-Wojtarowicz A., Jowsa A., Pawłowska-Góral K. et al.: Environ. Toxicol. Pharmacol. 1, 24 (2014).

Received: 23. 10. 2017 